\title{
Mitigation of Line Current Harmonics Using Shunt Active Filter With Instantaneous Real and Reactive Power Theory
}

\author{
M.Ramya, M.Sathyapriya, A.Benazir Hajira, P.Kumar \\ $P G$ Scholar-Dept of PG-ES, P.A. College of Engineering and Technology \\ PG Scholar - Dept of PG-ES, P.A. College of Engineering and Technology \\ $P G$ Scholar - Dept of PG-ES, P.A. College of Engineering and Technology \\ Assistant Professor, Dept of EEE, P.A. College of Engineering and Technology
}

\begin{abstract}
This paper present the mitigation of line current harmonics using control of shunt active power filter $(S A P F)$. The three phase system is connected to nonlinear load which cause harmonics to affect the power system. The control of shunt active power filter is not only compensating harmonics but also compensate reactive power. Voltage source inverter(VSI) at using SAPF reference current control strategies; instantaneous real and reactive power theory ( $p-q$ theory), modified synchronous rotating reference frame theory(Modified $d$ $q$ theory) with PI control and current control method at using hysteresis current control and SPWM controller. The different control technique of SAPF is based on reference current generation and current control method simulated by using MATLAB Simulink.
\end{abstract}

Keywords: shunt active power filter, harmonics, three phase system, voltage source converter, $p-q$ theory, $d-q$ theory, PI control, hysteresis current controller, SPWM controller.

\section{Introduction}

The power system at using time varying load and nonlinear load due to distortion of voltage and current waveforms which leads to failure of equipments. The nonlinear load at using uncontrolled rectifier, adjustable speed drives (ASDs), uninterrupted power supplies (UPS), etc,. The traditional passive filter is eliminating harmonics and simplest method but drawbacks of this method are resonant problem, low power factor and large size. So shunt active power filter is most commonly used because of better harmonics compensator and reactive power compensator due to improve the power factor.

The shunt active power filter is based on reference current calculation and current control techniques.The shunt active filter based reference current calculated by using two methods. They are frequency domain method (FDM) and time domain method (TDM). In FDM method reference current calculated based on Fourier Transform (FT), the most widely used FT are: Fast Fourier Transform (FFT) and Wavelet Transform (WT). The drawback of this method leads to a large amount of calculations, making the control method much more complicated and it requires at least one cycle to estimate the reference current, if it is failed to estimate reference current accurately then the current samples are corrupted with noise or transient. Due to this problem in FDM, TDM is used for reference current calculation, so that instantaneous real and reactive power theory (p$\mathrm{q}$ theory), modified synchronous rotating reference frame(SRF) theory (Modified d-q theory) is preferred.This work presents three phase system is connected to nonlinear load cause harmonics compensated based on SAPF. The control of SAPF based on different controller such as reference current calculation methods are $p-q$ theory and modified SRF theory with PI controller and current control methods are hysteresis and SPWM controllers.

\section{System Description}

In Fig. 1 shows the block diagram of three phase shunt active power filter. In three phase system is connected to nonlinear load and SAPF principle is inject current should be same magnitude but opposite phase shift with harmonics current. The harmonics are compensated by voltage source converter, in that three phase shunt active power filter is used. 


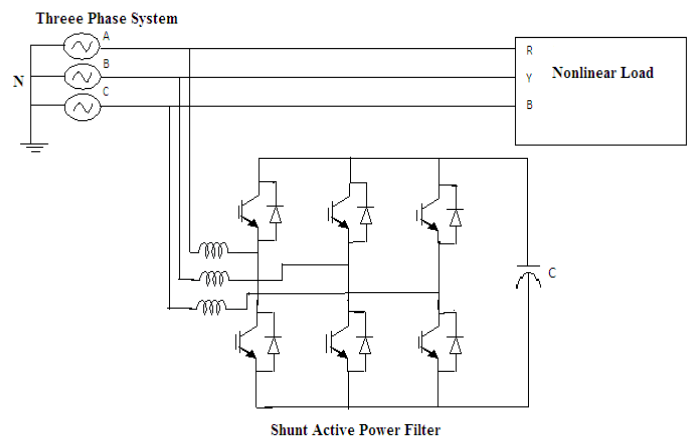

Fig.1 Block diagram of three phase SAPF

\section{INSTANTANEOUS REAL\&REACTIVE POWER THEORY - (p-q Theory)}

The p-q theory is based on set of instantaneous real and reactive power defined in time domain method It is valid for both steady state and transient state. This theory is efficient and flexible for designing shunt active filter. The three phase voltage and current $(\mathrm{abc})$ are converted into $\alpha \beta 0$ stationary reference frames. The Clarke and inverse Clarke transform of three phase voltage are given by,

$$
\begin{aligned}
& {\left[\begin{array}{c}
\mathrm{V} \circ 0 \\
\mathrm{~V} \alpha \\
\mathrm{V} \beta
\end{array}\right]=\sqrt{\frac{2}{3}}\left[\begin{array}{ccc}
\frac{1}{\sqrt{2}} & \frac{1}{\sqrt{2}} & \frac{1}{\sqrt{2}} \\
1 & -\frac{1}{2} & -\frac{1}{2} \\
0 & \frac{\sqrt{3}}{2} & -\frac{\sqrt{3}}{2}
\end{array}\right]\left[\begin{array}{l}
\mathrm{Va} \\
\mathrm{Vb} \\
\mathrm{V} c
\end{array}\right](1)} \\
& {\left[\begin{array}{l}
\mathrm{V} a \\
\mathrm{~V} b \\
\mathrm{~V} c
\end{array}\right]=\sqrt{\frac{2}{3}}\left[\begin{array}{ccc}
\frac{1}{\sqrt{2}} & 1 & 0 \\
\frac{1}{\sqrt{2}} & -\frac{1}{2} & \frac{\sqrt{3}}{2} \\
\frac{1}{\sqrt{2}} & -\frac{1}{2} & -\frac{\sqrt{3}}{2}
\end{array}\right]\left[\begin{array}{c}
\mathrm{V} \alpha \\
\mathrm{V} \beta \\
\mathrm{V} \circ 0
\end{array}\right](2)}
\end{aligned}
$$

Similarly three instantaneous line current $\mathrm{ia}, \mathrm{ib}$,ic can be converted into $\alpha \beta \circ$ coordinate,

$$
\begin{aligned}
& {\left[\begin{array}{c}
\mathrm{i} 0 \circ \\
\mathrm{i} \alpha \\
\mathrm{i} \beta
\end{array}\right]=\sqrt{\frac{2}{3}}\left[\begin{array}{ccc}
\frac{1}{\sqrt{2}} & \frac{1}{\sqrt{2}} & \frac{1}{\sqrt{2}} \\
1 & -\frac{1}{2} & -\frac{1}{2} \\
0 & \frac{\sqrt{3}}{2} & -\frac{\sqrt{3}}{2}
\end{array}\right]\left[\begin{array}{c}
\mathrm{ia} \\
\mathrm{ib} \\
\mathrm{ic}
\end{array}\right](3)} \\
& {\left[\begin{array}{c}
\mathrm{i} a \\
\mathrm{i} b \\
\mathrm{i} c
\end{array}\right]=\sqrt{\frac{2}{3}}\left[\begin{array}{ccc}
\frac{1}{\sqrt{2}} & 1 & 0 \\
\frac{1}{\sqrt{2}} & -\frac{1}{2} & \frac{\sqrt{3}}{2} \\
0 & -\frac{1}{2} & -\frac{\sqrt{3}}{2}
\end{array}\right]\left[\begin{array}{c}
\mathrm{i} 00 \\
\mathrm{i} \alpha \\
\mathrm{i} \beta
\end{array}\right](4)}
\end{aligned}
$$

The three phase instantaneous real, reactive and zero sequence power calculated by,

$$
\left[\begin{array}{c}
\mathrm{p} 0 \circ \\
\mathrm{p} \\
\mathrm{q}
\end{array}\right]=\left[\begin{array}{ccc}
\mathrm{V} \circ & 0 & 0 \\
0 & \mathrm{~V} \alpha & \mathrm{V} \beta \\
0 & \mathrm{~V} \beta & -\mathrm{V} \alpha
\end{array}\right]\left[\begin{array}{c}
\mathrm{i} 0 \circ \\
\mathrm{i} \alpha \\
\mathrm{i} \beta
\end{array}\right](5)
$$

The stationary reference frame at calculating compensated reference current represented by,

$$
\begin{aligned}
& \text { ic } \alpha \text { ref }=\frac{1}{V \alpha^{2}+V \beta^{2}}[V \alpha(P o-P)+V \beta q](6) \\
& i c \beta \text { ref }=\frac{1}{V \alpha^{2}+V \beta^{2}}[V \beta(P o-P)+V \alpha q](7)
\end{aligned}
$$

The inverse Clarke transform of three phases instantaneous compensated reference current given by, 


$$
\begin{gathered}
\text { ica ref }=\sqrt{\frac{2}{3}}\left[\left(\frac{-i \circ}{\sqrt{2}}\right)+\text { ic } \alpha \text { ref }\right] \\
\text { icb ref }=\sqrt{\frac{2}{3}}\left[\left(\frac{-i \circ}{\sqrt{2}}\right)-\frac{1}{2} i c \alpha \text { ref }+\frac{\sqrt{3}}{2} i c \beta \text { ref }\right](9) \\
\text { icc ref }=\sqrt{\frac{2}{3}}\left[\left(\frac{-i \circ}{\sqrt{2}}\right)-\frac{1}{2} i c \alpha \text { ref }-\frac{\sqrt{3}}{2} i c \beta \text { ref }\right](10)
\end{gathered}
$$

The instantaneous real and reactive power theory having some drawbacks, they are non sinusoidal voltage condition at unable to complete compensation of harmonics current.

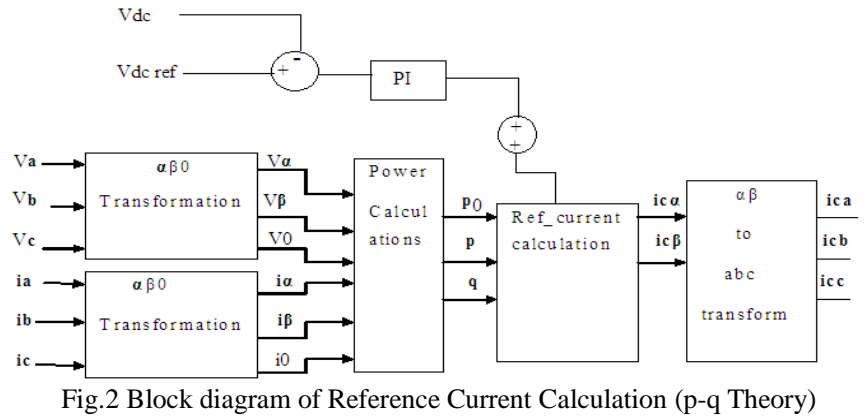

In fig. 2 shows the block diagram of reference current calculation, in that Clarke transform to calculate real, reactive and zero sequence power and stationary frame at compensated reference current generate by using PI controller. The SAPF at using DC link capacitor and DC link reference voltage and actual voltage compared to voltage to be regulated. Then inverse Clarke transform to calculate three phase compensated reference current.

IV. Modified Synchronous Rotating Reference Frame Theory -(Modified D-Q Theory)

The Modified d-q theory is based on set of rotating direct and quadrant power defined in time domain method. It is valid for both steady state and transient state. This theory is very efficient and flexible for designing shunt active filter in non sinusoidal voltage condition. The three phase voltage and current $(\mathrm{abc})$ are converted into dq0synchronous rotating reference frames. The park and inverse park transform of three phase current are given by,

$$
\begin{aligned}
& {\left[\begin{array}{c}
\mathrm{i} 0 \circ \\
\mathrm{i} \alpha \\
\mathrm{i} \beta
\end{array}\right]=\sqrt{\frac{2}{3}}\left[\begin{array}{ccc}
\frac{1}{\sqrt{2}} & \frac{1}{\sqrt{2}} & \frac{1}{\sqrt{2}} \\
1 & -\frac{1}{2} & -\frac{1}{2} \\
0 & \frac{\sqrt{3}}{2} & -\frac{\sqrt{3}}{2}
\end{array}\right]\left[\begin{array}{c}
\mathrm{ia} \\
\mathrm{ib} \\
\mathrm{ic}
\end{array}\right]} \\
& \theta \quad \theta=\tan ^{-1} \frac{V \beta}{V \alpha} \\
& {\left[\begin{array}{l}
i d \\
i q
\end{array}\right]=\left[\begin{array}{ll}
\cos (\theta \theta) & \sin (\theta \theta) \\
-\sin (\theta \theta) & \cos (\theta \theta)
\end{array}\right]\left[\begin{array}{l}
i \alpha \\
i \beta
\end{array}\right]}
\end{aligned}
$$

The three phase compensated reference current calculated by inverse park transform is given by,

$$
\begin{aligned}
& \text { ica ref }=i d \sin (w t)+i q \cos (w t) \\
& \text { icb ref }=i d \sin \left(w t-\frac{2 \pi}{3}\right)+i q \cos \left(w t-\frac{2 \pi}{3}\right) \\
& i c b \text { ref }=i d \sin \left(w t+\frac{2 \pi}{3}\right)+i q \cos \left(w t+\frac{2 \pi}{3}\right)
\end{aligned}
$$




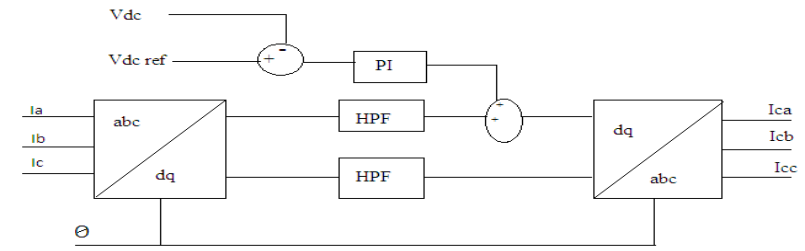

Fig.3 Block diagram of Reference Current Calculation (Modified d-q Theory)

In Fig. 3 shows the block diagram of shunt active power filter based Modified d-q theory. The three phases current is converted into rotating reference frame and passed to high pass filter (HPF), it attenuate higher order harmonics. The PI controller is to compare actual and reference DC link voltage to be regulated. The rotating frame coordinates dq converted into three phase compensated reference current Ica, Icb, Icc.

\section{Hysteresis Current Control}

The hysteresis current control is used to voltage fed converter to force these converter to behave as controlled ac current source to the power system.

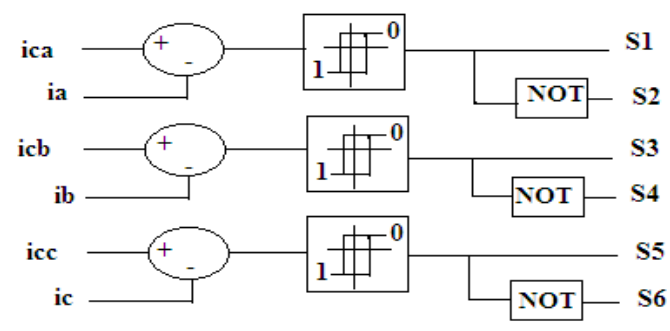

Fig.4 Hysteresis current controller

In Fig.4 shows the hysteresis current controller in that compensated reference current is compared to actual current to triggering of pulses and applied to shunt active filter. In this schemes upper and lower switches on and off condition based on compensated reference current is higher or lower the actual current. Then gate pulse given to shunt active filter of IGBT switches. The drawback of this scheme is increase switching frequency due to increase switching losses and high current ripples.

\section{SPWM Controller}

In Fig.5 shows the sinusoidal pulse width modulation (SPWM) controller, this method compensating reference current is compared to actual current of each phase and error signal is applied to PI controller. The PI controller output is compared to triangular wave of pulse width modulation techniques to generate gate pulse and applied to shunt active power filter.

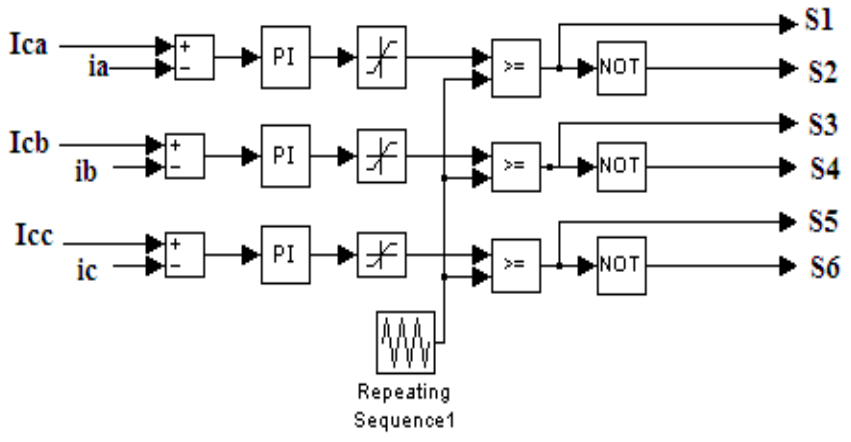

Fig.5 SPWM Controller

\section{Simulation and Result}

In Fig. 6 shows the simulation diagram of open loop system. The three phase system is connected to nonlinear load in that using three phase diode rectifier with RL load. The source and load side at three phase voltage and current measurement is connected. The source impedance is connected to compensate reactive power in power system. 


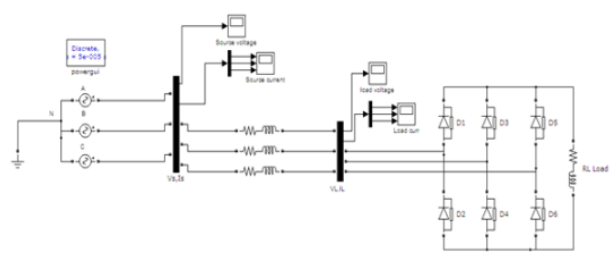

Fig.6 Simulation of open loop system

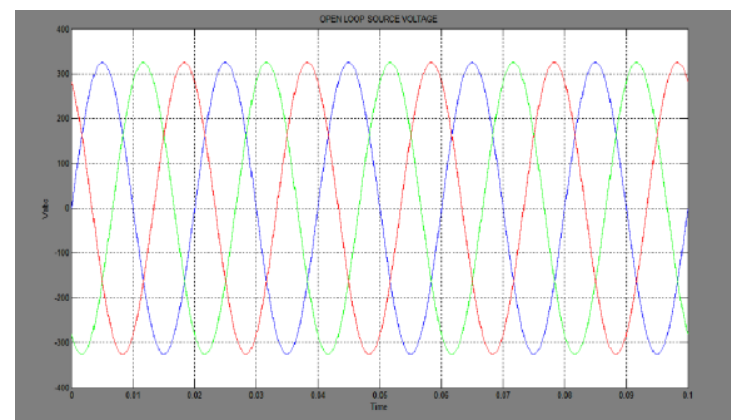

Fig.7 Waveform for open loop system three phase source voltage

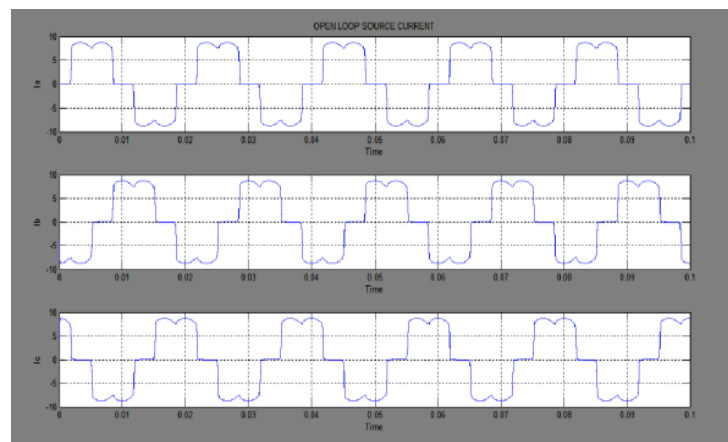

Fig.8 Waveform for open loop system three phase current

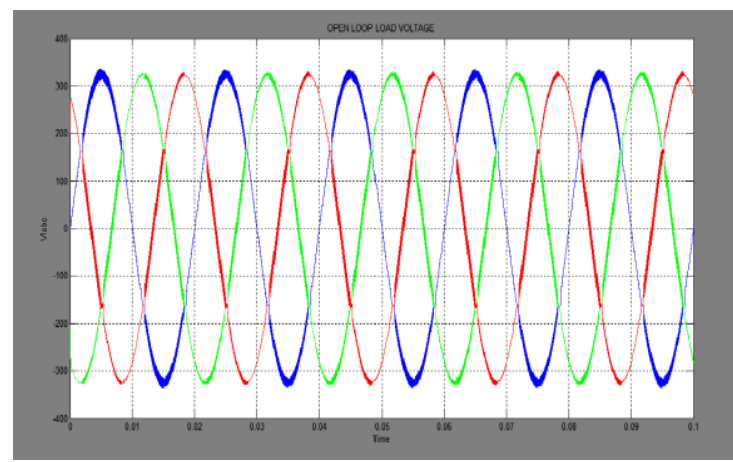

Fig.9 Waveform for open loop system three phase load voltage

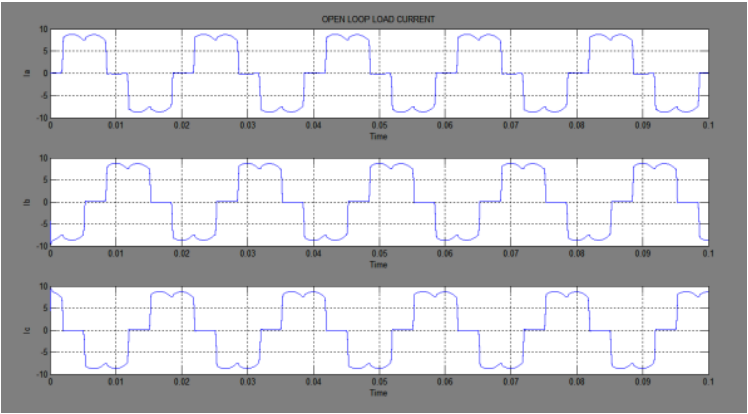

Fig.10 Waveform for open loop system three phase load current 


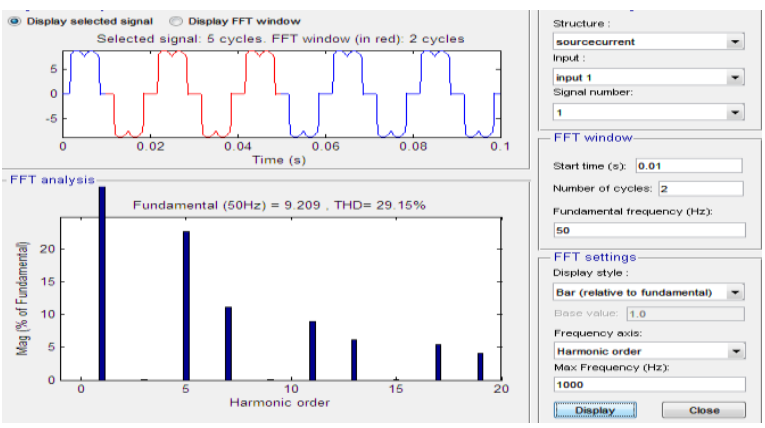

Fig.11 FFT analysis for source current before compensation

In fig.7 and fig. 8 shows the output waveform for open loop three phase source voltage $\mathrm{Va}, \mathrm{Vb}, \mathrm{Vc}$ and current ia,ib,ic. The source current should be distorted due to nonlinear load. In fig.9 and fig. 10 shows the output waveform for open loop three phase load voltage Vla,Vlb, Vlc and current Ila,Ilb,Ilc. The FFT analysis of open loop source current is $29.15 \%$. The source current is sinusoidal by using shunt active power filter.

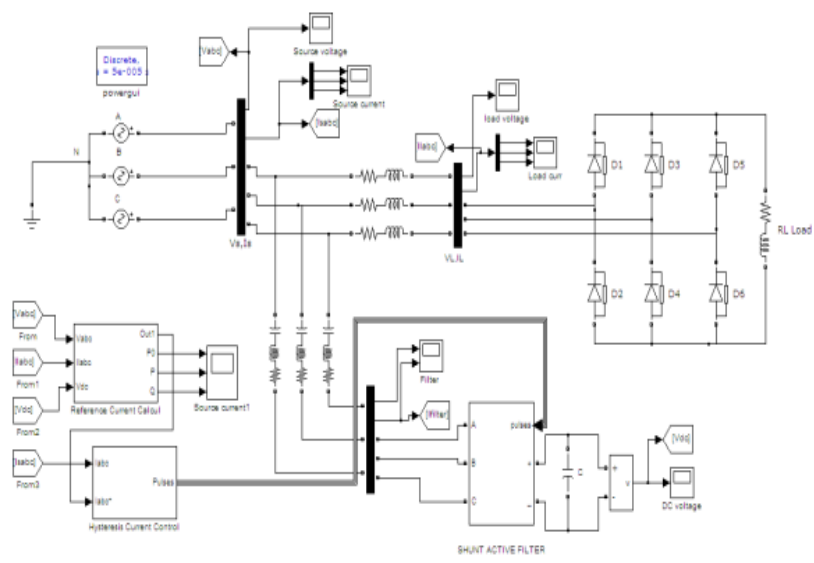

Fig.12 Simulation model of SAPF based p-q theory with hysteresis current control

In fig. 12 shows the simulation model of SAPF based p-q theory with hysteresis current control. The point of common coupling at connect shunt active power filter. In fig.13 shows the SAPF based reference current calculation of $\mathrm{p}-\mathrm{q}$ theory.

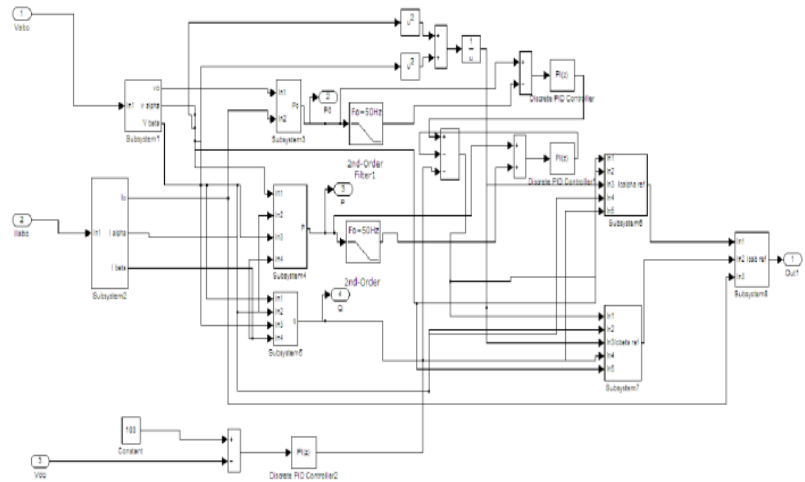

Fig.13 SAPF based p-q theory for reference current calculation

The generated reference current applied to hysteresis current controller and to trigger gate pulses to SAPF. In fig.14 and fig. 15 shows the waveform of three phase source voltage and source current in SAPF based p-q theory. The FFT analysis of source current should be 5.30\% in SAPF based p-q theory and current controlled by using hysteresis controller. 


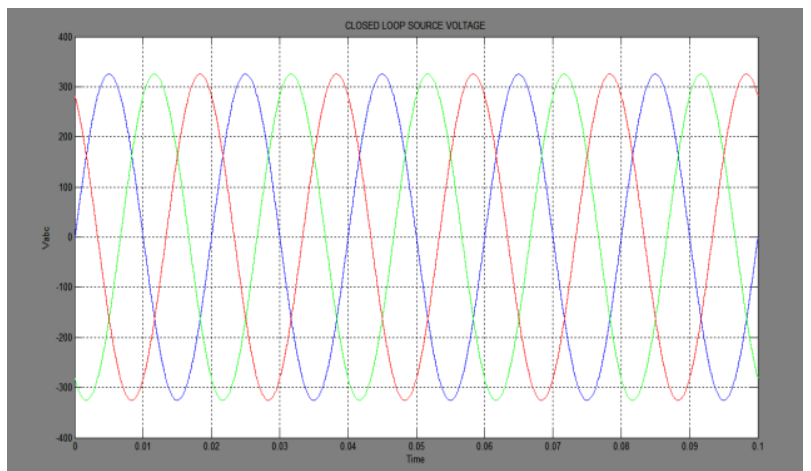

Fig.14 Waveform for three phase voltage SAPF based p-q theory

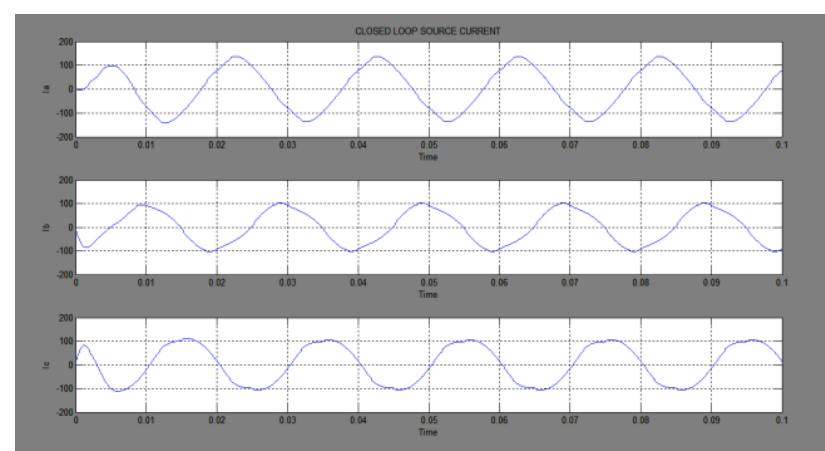

Fig.15 Waveform for three phase current SAPF based p-q theory
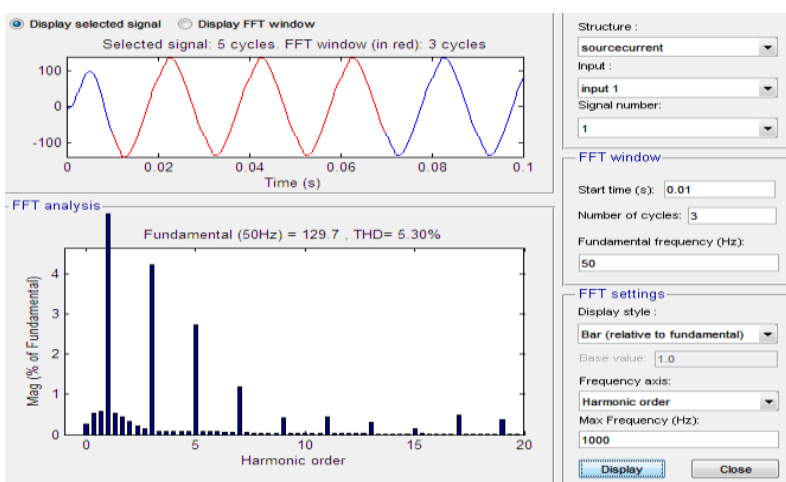

Display Close

Fig.16 FFT analysis of Source current in SAPF based p-q theory

In fig. 17 shows the simulation model of SAPF based modified d-q theory and current controlled by using SPWM controller. In fig. 18 shows the reference current calculation based modified d-q theory.

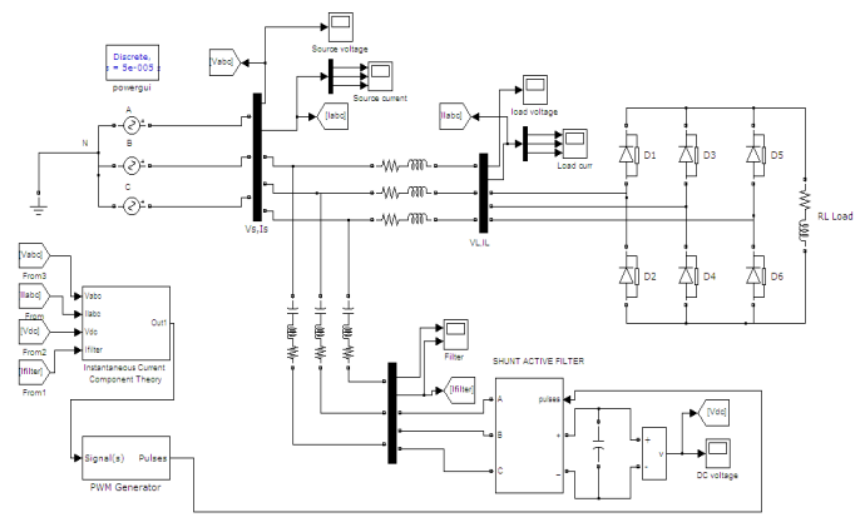

Fig.17 Simulation model of SAPF based modified d-q theory with SPWM control 


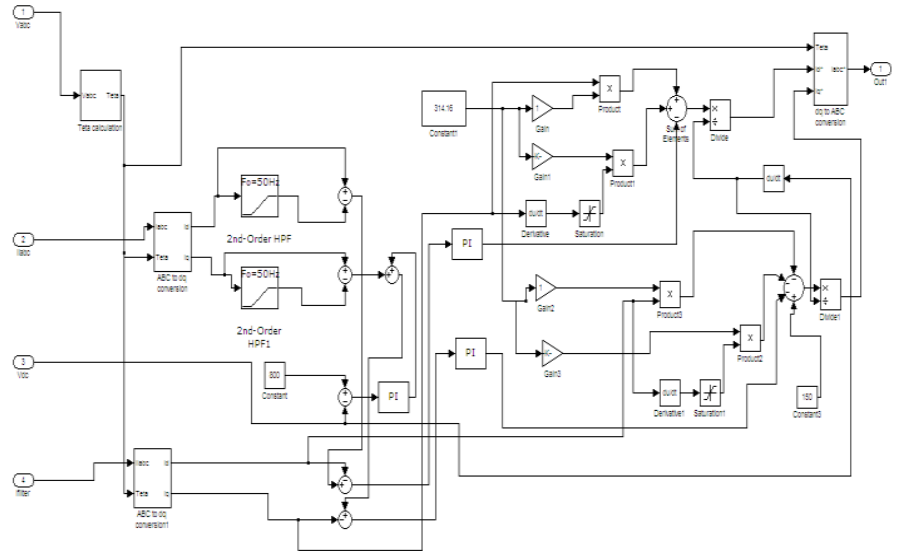

Fig.18 SAPF based modified d-q theory for reference current calculation

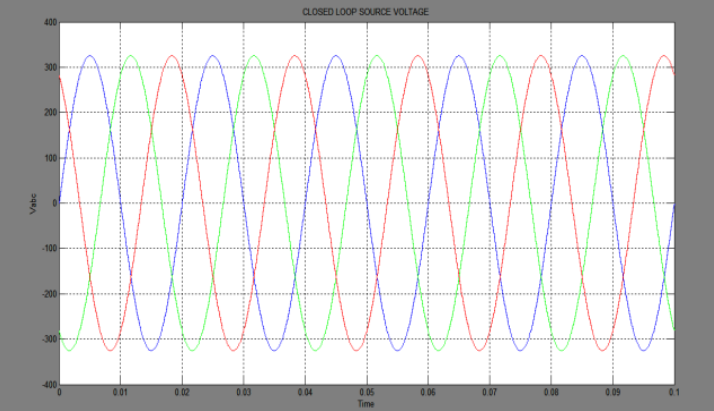

Fig.19 Waveform for three phase voltage SAPF based modified d-q theory

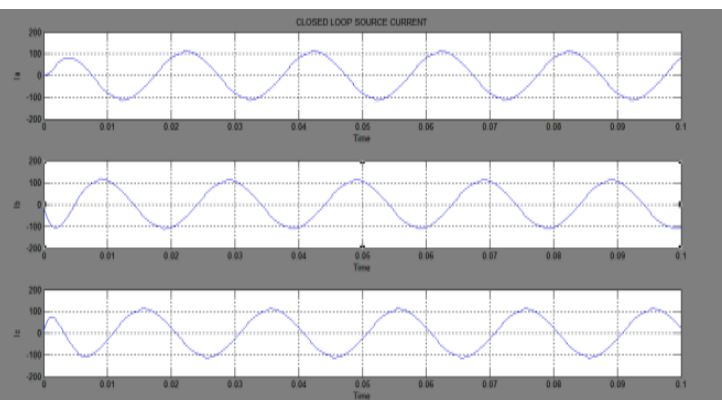

Fig.20 Waveform for three phase current SAPF based modified d-q theory

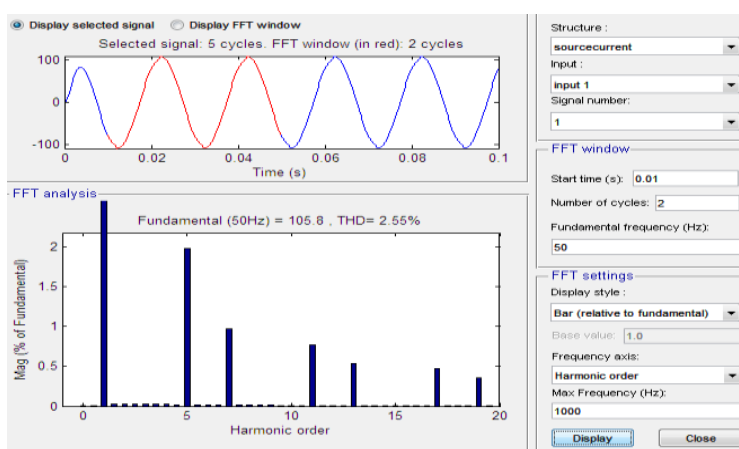

Fig.21 FFT analysis of Source current in SAPF based modified d-q theory

In Fig.19 and Fig.20 shows the three phase source voltage and current. The FFT analysis of source current should be $2.55 \%$ in SAPF based modified d-q theory and current controlled by using SPWM controller. Table A.1 gives the system parameters. 


\begin{tabular}{|l|l|}
\hline Parameter & Value \\
\hline Supply Voltage & $\mathrm{Vs}=230 * \sqrt{2}$ \\
\hline Source resistance & $\mathrm{Rs}=0.1$ ' $\Omega$ \\
\hline Source inductance & $\mathrm{Ls}=0.5 \mathrm{mH}$ \\
\hline Filter branch resistance & $\mathrm{Rf}=2 \Omega$ \\
\hline Filter branch inductance & $\mathrm{Lf}=2.5 \mathrm{mH}$ \\
\hline DC link capacitance & $\mathrm{Cdc}=3000 \mu \mathrm{f}$ \\
\hline DC link Voltage & $\mathrm{Vdc}=800 \mathrm{v}$ \\
\hline PI & $\mathrm{Kp}=0.6 \mathrm{Ki}=0.4$ \\
\hline Load resistance & $\mathrm{Rl}=15{ }^{\prime} \Omega$ \\
\hline Load inductance & $\mathrm{Ll}=60 \mathrm{mH}$ \\
\hline
\end{tabular}

VIII. Conclusion

In this paper SAPF based two control strategies compared in instantaneous real and reactive power theory and modified d-q theory and current control method at using hysteresis and SPWM controllers has been used for three phase system. In this method in source current harmonics compensated, improved power factor and THD value in IEEE 519 standard which thereby validate the satisfactory system performance.

\section{Reference}

[1] M. Chakravarthy, P. M. Sarma and S. N. Saxena," Comparative Studies of Different Control Strategies for Shunt Active Filter," ARPN Journal of Engineering and Applied Sciences, Vol. 6, No. 11, pp.27-35, Nov 2011.

[2] Leszek S. Czarnecki," Instantaneous Reactive Power p-q Theory and Power Properties of Three-Phase Systems," IEEE Transactions on Power Delivery,Vol. 21, No.1, pp.362-367, Jan. 2006

[3] VikashAnand and Dr. S. K. Srivastava," Performance Investigation of Shunt Active Power Filter Using Hysteresis Current Control Method,"JJERT, Vol.1, pp.1-8, June 2012.

[4] KanchanChaturvedi, Dr.AmitaMahor, AnuragDhar Dwivedi,"Active Power Filter Techniques for Harmonics Suppression in Non Linear Load, "IJECT, Vol.1, pp.123-127, April 2012.

[5] H.Akagi,"'Modern active power filter and traditional passive filter," Bulletin of the technical science, Vol.54, No.3, pp.255-269, 2006.

[6] Y.KusumaLatha, Ch.Saibabu, Y.P.Obulesh, "Control strategy for three phase shunt active power with minimum current,measurement,"IJECE,Vol.1,No.1,pp.31-42,Sep 2011.

[7] Moleykutty George and Kartik Prasad Basu,"Modeling and control of three phase shunt active power filter,"American Journal of applied science, pp.1064-1070, 2008

[8] Dr.RPrakask and Kiran R,"Modelling and simulation of active shunt filter for compensation of system harmonics,"IJEET, Vol.4, pp.172-179, June 2013.

[9] Marian P.Kazmierkowski and Luigi Malesani," Current control techniques for three phase voltage source PWM converter a survey,"IEEE trans., Vol.45, No.5, Oct 1998

[10] P Ramya and C N Arpitha," Reduction of THD in power system using generalized UPQC,'IJEETC, Vol.2, No.4, Oct 2013. 